\title{
Edible Mushrooms and Beta-Glucans: Impact on Human Health
}

\author{
Chiara Cerletti ${ }^{1, *(\mathbb{D}}$, Simona Esposito ${ }^{1}$ and Licia Iacoviello ${ }^{1,2} \mathbb{D}$ \\ 1 Department of Epidemiology and Prevention, IRCCS NEUROMED, 86077 Pozzilli, Italy; \\ simona.esposito@moli-sani.org (S.E.); licia.iacoviello@moli-sani.org (L.I.) \\ 2 Department of Medicine and Surgery, Research Center in Epidemiology and Preventive Medicine (EPIMED), \\ University of Insubria, 21100 Varese-Como, Italy \\ * Correspondence: chiara.cerletti@moli-sani.org; Tel.: +39-0865-915246
}

check for

updates

Citation: Cerletti, C.; Esposito, S.; Iacoviello, L. Edible Mushrooms and Beta-Glucans: Impact on Human Health. Nutrients 2021, 13, 2195. https://doi.org/10.3390/nu13072195

Academic Editor: Ashley J. Snider

Received: 10 May 2021

Accepted: 22 June 2021

Published: 25 June 2021

Publisher's Note: MDPI stays neutral with regard to jurisdictional claims in published maps and institutional affiliations.

Copyright: (C) 2021 by the authors. Licensee MDPI, Basel, Switzerland. This article is an open access article distributed under the terms and conditions of the Creative Commons Attribution (CC BY) license (https:/ / creativecommons.org/licenses/by/ $4.0 /)$.

\begin{abstract}
Mushroom cell walls are rich in $\beta$-glucans, long or short-chain polymers of glucose subunits with $\beta-1,3$ and $\beta-1,6$ linkages, that are responsible for the linear and branching structures, respectively. $\beta$-glucans from cereals, at variance, have no 1,6 linkages nor branching structures. Both immunomodulatory and anti-inflammatory effects of mushrooms have been described using purified $\beta$-glucans or fungi extracts on cellular and experimental models; their potential clinical use has been tested in different conditions, such as recurrent infections of the respiratory tract or complications of major surgery. Another promising application of $\beta$-glucans is on cancer, as adjuvant of conventional chemotherapy. $\beta$-glucans may protect the cardiovascular system, ameliorating glucose, lipid metabolism, and blood pressure: these activities, observed for oat and barley $\beta$-glucans, require confirmation in human studies with mushroom $\beta$-glucans. On the other hand, mushrooms may also protect the cardiovascular system via a number of other components, such as bioactive phenolic compounds, vitamins, and mineral elements. The growing knowledge on the mechanism(s) and health benefits of mushrooms is encouraging the development of a potential clinical use of $\beta$-glucans, and also to further document their role in preserving health and prevent disease in the context of healthy lifestyles.
\end{abstract}

Keywords: mushrooms; $\beta$-glucans; immune modulation; cancer adjuvant; microbiota; cardiometabolic system; healthy diet

\section{Introduction}

Edible mushrooms are tasty and nutritious macro-fungi with fruiting bodies and mycelia, both spontaneous or cultured, belonging to the classes of Basidiomycetes and Ascomycetes. They represent a very small part of the about 150,000-160,000 species estimated to be present on earth. Within the 2000 species known as safe, although not all edible, 700 have reportedly pharmacological properties. Besides the pre-historical finding in the Italian Alps of a mushroom in possession of the Ice Man mummy discovered in 1991, possibly as a laxative for intestinal disease [1], the use of mushrooms as medicaments had already significantly spread in the cultures of ancient Greece, Rome, China, and India, and for centuries they have been part of the traditional oriental medicine: the health properties of these vegetables varied from dietary to nutraceutical, medical, and psychotropic effects [2].

Only in the last decades, however, scientific studies were dedicated to the comprehension of the biological mechanisms underlying mushroom beneficial effects. A recent PubMed search by "mushroom and health" as keywords, resulted in 2411 publications (on 21 April 2021); of these, almost 80 were reviews from 2020 to date. This underlines the actual great interest of nutritionists, biologists, and medical doctors on the scientific bases of mushrooms' healthy properties.

In the present review we will focus on $\beta$-glucans as important constituents of mushrooms. Their beneficial health effects and related mechanisms are the main object of this review. $\beta$-glucans from yeast and cereals will be only considered as reference. 


\section{Chemical Structure of $\beta$-Glucans}

Glucans constitute the cell wall of fungi and yeast, and are the main polysaccharides present in mushrooms, in addition to water (90\%), proteins, and amino acids (10-40\%), fats $(2-8 \%)$, vitamins and antioxidants, residual salts, and metals. Total carbohydratesincluding polysaccharides-are about $50 \%$ of the dry matter of mushrooms.

The macromolecular structure of mushroom $\beta$-glucans consists of D-glucose monomers linked by $\beta$ type glycosidic linkages at two differing positions, 1,3 and 1,6, responsible for the linear structure and of the main branching, respectively; in the $\alpha$-glucans, proportionally less frequent in mushrooms, the polymers contain $\alpha$ type links. $\beta$-glucans from yeast have similar structures to those from fungi, the 1,3 linkages being more frequent (about $85 \%$ ), in respect to the 1,6 . Cereals are another important food source of $\beta$-glucans, which have 1,3 and 1,4 but no 1,6 linkages and branching structures. Though all $\beta$-glucans are similar in terms of type of glycosidic bonds linking together the glucose molecules, the structural build-ups of $\beta$-glucans varies in chain lengths, glycosidic bond positions, degree of branching, and three-dimensional structures (Figure 1).

A

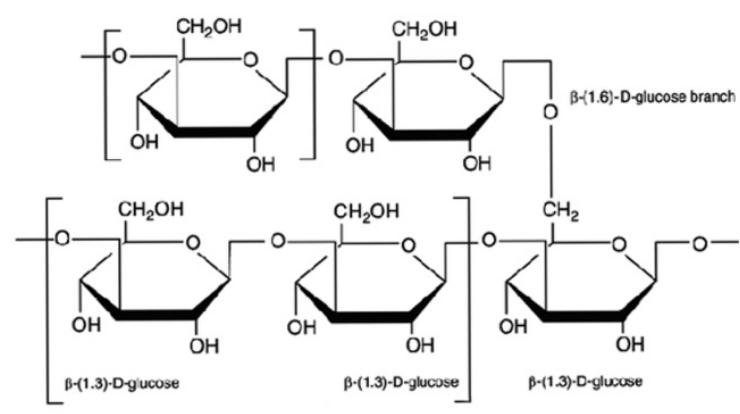

B

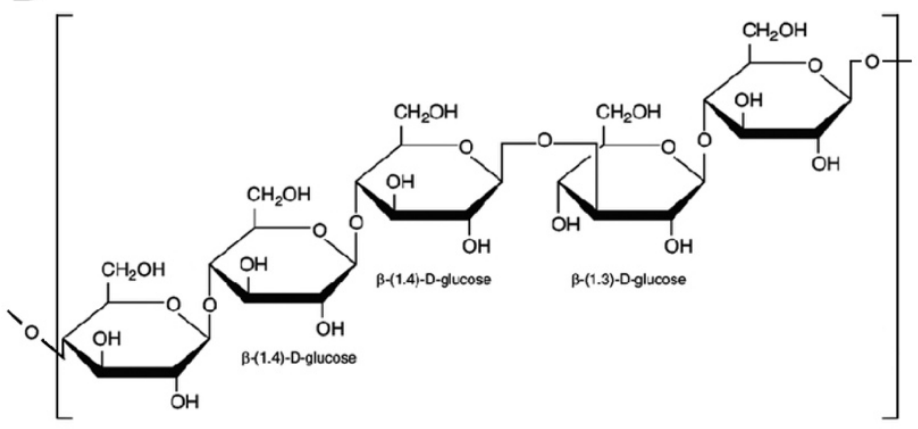

Figure 1. Chemical structures of $\beta$-glucans. The side branches of mushroom $\beta$-glucans (A) are attached to the $\beta-1,3-D$-glucan main chain by a $\beta-1,6$ linkage, and may consist of one or several $\beta$-D-glucose units; cereal $\beta$-glucans (B) are linear and consist of D-glucose molecules linked by 1,3 $\beta$ and $1,4 \beta$ - linkages.

Structural and physical characteristics of $\beta$-glucans vary from different species, cultivars, and also from growing environments, drying conditions of fungi and isolation/extraction methods of the $\beta$-glucans, with consequent important changes in the intensity and type of activities.

\section{Pharmacokinetics of $\beta$-Glucans}

A recently published study [3] reported the pharmacokinetics of lentinan, the $\beta$-glucan isolated from the fruiting body of shiitake mushroom (Lentinula edodes) after intravenous administration of $32 \mathrm{mg} / \mathrm{kg}$ of fluorescent labelled lentinan to rats. The circulating plasma levels of lentinan decreased with an apparent biphasic elimination; tissue distribution showed that most of the administered lentinan was concentrated in the liver, followed by kidney, spleen, heart, stomach, and intestine. The slow degradation of lentinan in the 
liver, recovered up to seven days, was confirmed by liver perfusion methods and liver microsome assays, which indicated that CYP450 enzymes (mainly CYP2D6 and CYP2C9) and epoxide hydrolase are involved in the metabolic degradation of this polysaccharide in the liver. These data confirm and extend previous pharmacokinetic studies in rats and other animal species by the use of radio labelled lentinan [4]. Pharmacokinetic studies of lentinan (as of other $\beta$-glucans) are limited by the lack of a specific detection method: lentinan was usually detected by the Limulus amebocyte lysate test (G-test) based on its typical triple helix conformation [5], but possibly disturbed by endotoxins or by other $\beta$-glucans. $\beta$-glucans, probably of dietary origin, are detectable in serum of healthy subjects with levels below $60 \mathrm{pg} / \mathrm{mL}$; raised levels are a marker of invasive fungal infections, detectable by commercially available assays [6,7].

The pharmacokinetics of lentinan was detected by the Limulus test in the blood of 10 healthy volunteers and of three patients with advanced gastric cancer: peak plasma levels $(50-70 \mathrm{ng} / \mathrm{mL})$ were reached at the end of a $2 \mathrm{~h}$ intravenous infusion of $1-4 \mathrm{mg}$ of lentinans, and declined slowly over seven days, mainly due to uptake or degradation in the liver [8].

No reports on the absorption and pharmacokinetics of orally administered $\beta$-glucans are available, even though there are several reports of their biological effects. As specified below in the paragraph " $\beta$-glucans in metabolic and gastro-intestinal system", mushroom $\beta$-glucans are not digested in the human gastro-intestinal tract, reaching the bowel virtually unchanged; $\beta$-glucans form a gel at the mucosa surface, which modulate biliary salt resorption, and modify the intestinal microbiota. In addition, small and large fragments of $\beta$-glucans found in the serum indicate that they may also be absorbed from the intestinal tract [9]. Macrophages within the Payer's patches in the intestine physically transport the insoluble whole glucan particles into the gut-associated lymphoid tissue.

\section{4. $\beta$-Glucans Biological Effects}

Within the $\beta$-glucan health-related effects, the most studied and characterized are the modulation of the immune system and metabolic and gastrointestinal effects. Han et al. [10] carefully reviewed the information on structure-function relationship of $\beta$-glucans in relation to cellular immune modulation and antitumor activities: molecular weight, degree of branching, length of the sidechains, conformation of sugar residues, and consequent tridimensional structure, degree of solubility, and particulate size appear to be the most important features of $\beta$-glucans immune recognition, although some literature data are often inconsistent or contradictory.

\subsection{Immunomodulatory and Anti-Inflammatory Effects}

$\beta$-glucans ingested as food or supplement reach the small intestine without any gastric digestion; they are then internalized by the intestinal epithelium and/or by the macrophages and presented to the immune cells within the Peyer's patches in the intestine, and in distal lymphoid organs. Specific receptors of $\beta$-glucans are the Toll-like (TLR) and the C-type lectin-like receptors: within the latter, dectin-1 is the best characterized one and is predominantly expressed on the surface of monocyte/macrophages, neutrophils, and dendritic and natural killer (NK) cells [11,12]. An intracellular signal transduction follows the receptor recognition step and results in activation of the nuclear factor k-lightchain-enhancer of activated B cells (NF-kB), transcription of inflammatory-immune genes, production of cytokines, nitric oxide (NO), and reactive oxygen species (ROS) $[2,13,14]$. Other pattern recognition receptors (PRR) are implicated in $\beta$-glucan recognition and may act in cooperation with dectin-1/TLR [15], or even directly [16]. During injury, $\beta$-glucan receptors may be blocked, but a strong immunomodulatory response, independent of these receptors, can be stimulated, for instance, by $\beta$-glucans from a fungal pathogen, with expression of high levels of the interleukin-1 receptor antagonist (IL-1RA) [16]. Lentinan has been shown to upregulate cytokines in mouse macrophages and to attenuate IL-1 $\beta$ secretion resulting from Listeria activation of the absent in melanoma 2 (AIM2) inflam- 
masome. Importantly, lentinan was able to reduce endotoxin lethality in mice despite the up-regulation of cytokine expression, most probably via inhibition of non-canonical inflammasome activation [17]. Similarly, $\beta$-glucans from Saccharomyces cerevisiae were reported to protect against endotoxin-induced shock and organ injury in rats, although the precise mechanism was not established [18]. In this context, it is worth mentioning that in mice treated with indomethacin, a bacterial $\beta$-glucan extract (Sinofilan) may contribute to septic shock, which occurs through translocation of enterobacterial flora to various organs, and systemic inflammation [19]; the lethality of the indomethacin- $\beta$-glucan combination was not confirmed by others [20], using several different types of $\beta$-glucans. The discussion of this experimental model, however, is outside the scope of this article and the reader is referred to original works.

$\beta$-glucans from Lentinus edodes inhibited lipopolysaccharide (LPS)-induced NO and tumor necrosis factor (TNF) $\alpha$ release by a macrophage cell line Please confirm whether you need to use italics and gene expression of iNOS mRNA and TNF $\alpha$ mRNA [21]. An extract of the edible oyster mushroom reduced the release of TNF $\alpha$ and IL- 6 by LPS-challenged monocyte in vitro, and also in vivo in mice challenged with LPS, after administration of the mushroom extract [22].

Two different $\beta$-glucan extracts from Lentinus edodes exerted different immunomodulatory activities: the commercial extract, containing higher amounts of $\alpha$-glucans with respect to $\beta$-glucans, reduced the production of pro-inflammatory cytokines, transforming growth factor (TGF)- $\beta$ and IL-10, and the oxidative stress-induced apoptosis, while the in-house extract attenuated late apoptosis [23].

An extract from Agaricus blazei, known to be pro-inflammatory in vitro, reduced cytokine levels in human blood of healthy volunteers after oral intake for several days of the mushroom extract [24].

The lentinan exerted a significant anti-viral activity on infected epithelioma cells, by both direct inactivation and inhibition of viral replication: the lentinan effect was attributed to the regulation of the innate immune responses and specific immunity, in addition to the down-regulation of the inflammatory TNF- $\alpha$, IL-2, and IL-11 and up-modulation of IFN- 1 and IFN- $\gamma$ after the viral challenge [25]. The antiviral and anti-inflammatory effects of mushrooms have been recently reviewed and suggested as therapeutic potential to be developed against SARS-CoV-2 [26].

\section{2. $\beta$-Glucans in Pre-Clinical Experimental Models}

The reported [17,21-24], apparently discrepant, results on the immunomodulatory and anti-inflammatory effects of mushroom $\beta$-glucans may be partly explained by the great heterogeneity of mushrooms, different extraction techniques of $\beta$-glucans, and in vitro or in vivo models of testing, and confirm complex and not completely understood mechanisms.

Nevertheless, their potential clinical use is of great value and is being considered in different pre-clinical experimental models and in clinical studies. $\beta$-glucans from mushrooms effectively improved the immune response or survival in different experimental models of sepsis, such as pulmonary sepsis induced by intra-tracheal administration to rats of antibiotic-resistant Klebsiella pneumoniae [27], or cryptococcal infection in mice [28]. Lentinan exerted intestinal anti-inflammatory activity in a mouse model of colitis, through inhibition of IL-8 mRNA expression [29] and improved the intestinal barrier function in piglets, decreasing rotavirus-induced diarrhea [30].

\section{3. $\beta$-Glucans in Infections and Allergy}

The immunomodulatory effect of $\beta$-glucans (a syrup containing the pleuran $\beta$-glucan from Pleurotus ostreatus and vitamin $C$ ) has been tested versus vitamin $C$ alone in a clinical trial in children with recurrent respiratory tract infections [28]: the respiratory symptoms were reduced, but the beneficial effect cannot be attributed to the $\beta$-glucans alone, rather should be related to a potentiating effect by $\beta$-glucan of vitamin C [31]. The Shiitake mushroom extract Lentinex ${ }^{\circledR}$ given as a supplement in a cross-over, placebo-controlled trial 
in healthy elderly was safe and induced an increase in the number of circulating B-cells, without affecting any other immune parameter [32]. A randomized, double-blind, placebocontrolled study with pleuran, the $\beta$-glucan isolated from Pleurotus ostreatus, showed a significant reduction of peripheral blood eosinophilia and stabilized the levels of total immunoglobulin (Ig)E in serum in children with recurrent respiratory tract infections, suggesting a potential anti-allergic effect of mushroom-derived $\beta$-glucans [33].

Few studies on autoimmune diseases have been performed: AndoSan ${ }^{\mathrm{TM}}$, an extract derived from Agaricus Blazei Murill by more than $80 \%$, was tested in inflammatory bowel disease, Crohn disease, and ulcerative colitis with modest results on inflammatory cytokines or clinical symptoms [34,35].

\section{4. $\beta$-Glucans as Adjuvants in Oncological Disorders}

No direct cytotoxic effect on cancer cells was reported for $\beta$-glucans, but their adjuvant activity was shown in mice concomitantly treated with anti-tumor monoclonal antibodies, the dual treatment resulting in mammary and hepatic tumor regression significantly greater than each single treatment [36]. The adjuvant mechanism of immune system activation depends on the formation of an immune complex of $\beta$-glucans, after recognition as PAMP, with anti- $\beta$-glucan antibodies, which through immune effector cells and $\mathrm{C} 3$ phagocytes facilitates killing of tumor cells, as represented in Figure 2 [37].

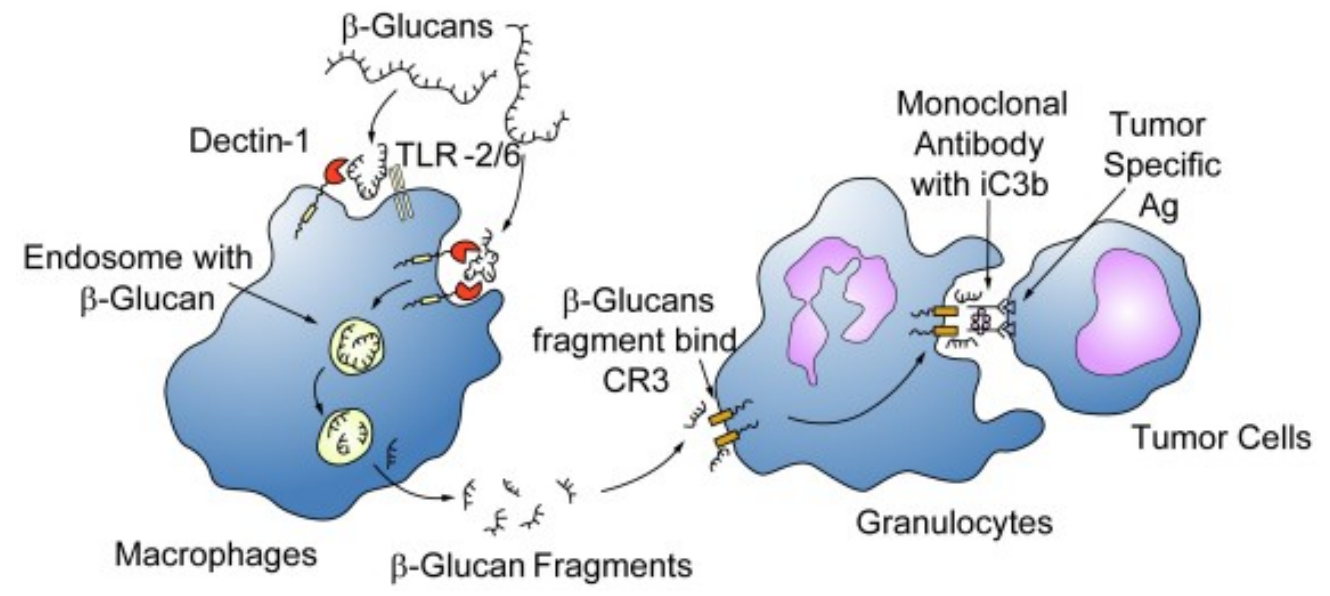

Figure 2. Schematic effect of $\beta$-glucans on immune and cancer cells. $\beta$-glucans are captured by the macrophages via the Dectin-1 receptor with or without TLR-2/6, internalized, fragmented into smaller fragments, carried to the marrow and endothelial reticular system and subsequently released. These small $\beta$-glucan fragments are eventually taken up by circulating granulocytes, monocytes or macrophages via the complement receptor (CR)3 and the immune responses turned include phagocytosis of the monoclonal antibody tagged tumor cells. From [37] with permission.

The major roles of mushroom-derived $\beta$-glucans on cancer progression have been extensively reviewed [38]. A promising application of $\beta$-glucans is their use in cancer treatment, as adjuvant of conventional therapies. A number of clinical trials, phase 1 and 2 studies, registered on clinicaltrials.gov and listed in recent reviews $[13,39,40]$ are ongoing on different tumor types, including pancreatic, head and neck cancer, non-small cell lung carcinoma, non-Hodgkin's lymphoma, colorectal cancer, neuroblastoma, and triple negative breast cancer. Most clinical trials have been testing registered $\beta$-glucan extracts from yeast, such as Imucell ${ }^{\mathrm{TM}}$ WBG or BTH1677 (Imprime PGG), in combination with PD-1 (programmed death receptor) blocking antibody or immune checkpoint inhibitors or with conventional treatments. Few of these studies have been completed and the results published so far support that these products are well tolerated and safe and could improve the remission rate as first line treatment, combined with conventional chemotherapy in nonsmall cell lung carcinoma patients [41,42], or with immunotherapy in colorectal cancer [43].

Within the mushroom $\beta$-glucans, lentinan has been tested in different clinical settings. A meta-analysis on 650 individual patient data showed that addition of lentinan to 
standard chemotherapy significantly prolonged the survival of patients with advanced gastric cancer in respect to chemotherapy alone [44]. Lentinan prolonged the survival of gastric cancer patients receiving fluoropyrimidine (S-1)-based chemotherapy; the ratio of granulocytes/lymphocytes was significantly higher in the patients receiving lentinan compared to the controls with chemotherapy alone, supporting an immunological effect of lentinan [45]. Zhang et al. [46] reviewed the randomized controlled trials published from 2004 to 2016, conducted in China to test lentinan in combination with chemotherapy in lung cancer patients. In the 38 trials analyzed with 3117 total participants, lentinan administered intravenously (1-1.5 mg/day for two to eight weeks) improved the patients' quality of life and increased the overall response rate of chemotherapy (56\% versus $43.3 \%$ of chemotherapy alone).

A recent systematic review of clinical trials on fungal $\beta$-glucans in cancer patients reports that on 16 trials with a total of 1650 patients the administration of $\beta$-glucans is safe and well-tolerated and that their administration concomitant with chemo or radiotherapy reduced the immune depression caused by such treatments and accelerated the recovery of white blood cell counts; however, these conclusions are still controversial, due to some not statistically significant findings and to a great diversity among trial methodologies or lack of information [47].

\section{5. $\beta$-Glucans in Metabolic and Gastro-Intestinal Systems}

The mushroom $\beta$-glucans are not digested in human gastrointestinal tract, as the enzymes secreted by intestinal brush border epithelial cells are unable to hydrolyze $\beta$-glycosidic bonds; within other properties, they speed up the transit of bowel contents, increasing fecal bulk and frequency, with possible beneficial properties of protection from irritable bowel syndrome, diverticular diseases, and colon cancer [13].

$\beta$-glucans lower cholesterol levels, through different reported mechanisms, still not completely understood [48]. Acting as prebiotics, $\beta$-glucans has been associated to the production of short-chain fatty acids (SCFA) by intestinal microflora fermentation, which are able to inhibit cholesterol synthesis, by inhibition of the hydroxymethylglutarylcoenzyme A (HMG-CoA) reductase, and to increase LDL-cholesterol catabolism. In addition, $\beta$-glucans, by forming a gel on the mucosal surface of the bowel, inhibit intestinal resorption of the bile salts and stimulate their neo-synthesis in the liver. As a consequence, increased biliary salts activate utilization of circulating cholesterol, thus reducing its level in the blood (Figure 3). Dietary fibers also bind lipids and cholesterol and decrease absorption at the intestinal level and increase the fecal excretion of these substances. Modulation of cholesterol-related genes by a glucan fraction of Pleurotus ostreatus was shown in a mice model [49].

\subsection{1. $\beta$-Glucans from Cereals and the EFSA Health Claims}

The $\beta$-glucans from cereals, due to their 1,3 and 1,4 linkages, are recognized by the organism as non-digestible dietary fibers and exert different metabolic activities, which positively influence the cardiovascular system: they have been shown to lower cholesterol, triglycerides and apolipoprotein B in adult subjects; several trials have been reviewed in two meta-analyses, considering diets enriched with oat and barley $\beta$-glucans, respectively [50,51]; systolic and diastolic blood pressure were also reduced in mild or borderline hypertensive patients [52], and in hypertensive obese men and women [53], glycemic and insulinemic responses were reduced by oat $\beta$-glucans at increasing viscosity given with breakfast to healthy subjects, without modifying appetite or food intake [54]. 


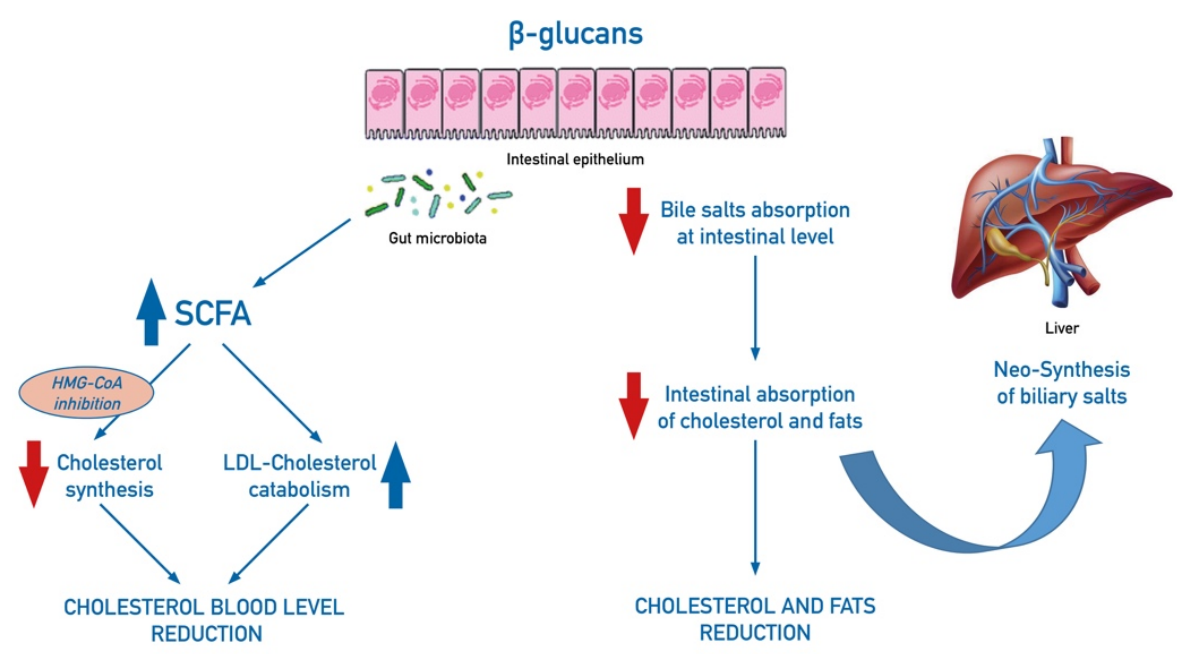

Figure 3. Schematic mechanisms of effect of dietary intake of $\beta$-glucans on cholesterol balance. $\beta$-glucans increase the production of short-chain fatty acids (SCFA) by intestinal microflora fermentation: SCFA inhibit cholesterol levels by acting on its synthesis, through inhibition of the hydroxymethylglutaryl-coenzyme A (HMG-CoA) reductase, and by increasing LDL-cholesterol catabolism. In addition, $\beta$-glucans, by forming a gel on the mucosal surface of the bowel, inhibit intestinal resorption of biliary salts, cholesterol, and fats and stimulate neo-synthesis of biliary salts in the liver.

A beverage enriched with 5 or $10 \mathrm{~g}$ of $\beta$-glucans from oats (but not from barley) administered for eight weeks decreased total cholesterol and postprandial glucose and insulin concentrations in hypercholesterolemic subjects [55]; several trials showed in type 2 diabetes patients reduced fasting blood glucose levels and glycosylated hemoglobin percentages upon supplementation with fibers or beta-glucans from cereals and an umbrella meta-analysis of meta-analyses and trials on type 2 diabetic receiving $\beta$-glucans or psyllium fibers summarizes these interesting results [56].

Within the different mechanisms at the basis of the reported cardiometabolic effects of $\beta$-glucans, changes of gut microbiota and stimulation of colon commensal bacteria, such as Lactobacilli and Bifidobacteria species, have been considered part of the final (beneficial) effects on bile acids, small-chain fatty acid signaling and cholesterol metabolism regulation and also on the immunomodulatory effects already reported in this review (see for review [57]).

In 2011 the European Food Safety Authority (EFSA) Panel on Dietetic Products, Nutrition and Allergies addressed "the scientific substantiation of health claims in relation to $\beta$-glucans from oats and barley and maintenance of normal blood LDL-cholesterol concentrations, increase in satiety leading to a reduction of postprandial glycemic responses, and digestive function" [58]. The LDL-cholesterol level lowering effect in the general population had been already accepted as a claim in 2009 by the same panel; to obtain a postprandial glycemic reduction, $4 \mathrm{~g}$ of $\beta$-glucans from oats or barley for each $30 \mathrm{~g}$ of available carbohydrate should be consumed by an individual who wishes that; the latter digestive function was not sufficiently defined [59].

\subsection{2. $\beta$-Glucans from Mushrooms}

Similar beneficial physiologic effects on the cardio-metabolic system have been reported also for $\beta$-glucans from mushrooms in numerous in vitro cell systems and in animal experiments, with attention to the main mechanisms involved [60], while the studies in humans supporting these effects are scarce.

A recent systematic analysis reviewed the human intervention studies on Pleurotus ostreatus (or oyster mushroom), one of the most common edible mushrooms worldwide, eaten fresh or cooked or in dried form, on cardiometabolic parameters and reported some beneficial effects on glucose and lipid metabolism, and partly blood pressure [61]. The 
authors, however, considered with cautions the reported effects, due to the small number of subjects studied and to the trial designs not sufficiently controlled and adequate [61].

A $\beta$-glucan-enriched mixture, corresponding to $3.5 \mathrm{~g} /$ day of fungal $\beta$-glucans, obtained from Shiitake mushrooms and incorporated in three different commercial food creams, was given to hypercholesterolemic subjects, in a controlled, randomized, doubleblind trial. After eight-week intervention, no changes in lipid- or cholesterol-related parameters were reported in either subjects receiving $\beta$-glucans or placebo; no differences were also observed in the concentrations of inflammatory cytokines (IL-1 $\beta$, IL-6, and TNF$\alpha$ ) or oxidized LDL, at the end of the intervention in the two groups. On the other hand, interestingly, in the same trial the mushroom mixture modulated the microbiota differently from placebo, cholesterol and dietary fiber intake being the most associated factors to the observed microbiota variations [62].

Although suggestive and supportive of future larger studies, $\beta$-glucans from mushrooms, at variance to those from oats and barley, do not seem to beneficially affect lipid levels and glycemic responses in humans. Besides differences in trial designs, power calculations, and type of subjects included in the studies (healthy, hypercholesterolemic, diabetic subjects, and elderly), the different mushroom species used as source of $\beta$-glucans may have contributed to the uncertain findings. The chemical structure of $\beta$-glucans and the degree of branching with substituents or protein/peptide links define the molecule tridimensional conformation and may influence the water solubility and the biological activities of the $\beta$-glucans derived from different mushroom species.

The $\beta$-glucan content in different cultivars of Lentinula edodes, determined by a specific kit (Megazyme International, Ireland), ranged from 20 to $40 \%$ and from 33 to $58 \%$, respectively, in the pileus and the stipe regions of the dried fruiting bodies [63]; these values of $\beta$-glucan content were confirmed by two subsequent studies detecting $\beta$-glucans in a large number of fruiting bodies of wild and commercial edible mushroom species, including the Lentinula edodes $[64,65]$. The latter study assayed $\beta$-glucans also with the Congo red method, which detects the $\beta$-glucans with a triple-helix chain conformation, possibly characterized by more efficient immunomodulatory activities [10]. Table 1 reports all glucan and $\beta$-glucan content in different species and parts of commercially cultivated mushrooms [64]. The $\alpha$-glucan content in mushrooms was only a small percentage of total glucans, even less than $1.5 \%$ in some Lentinula edodes cultivars [63-65].

Table 1. All glucans and $\beta$-glucan content in different commercially cultivated mushrooms.

\begin{tabular}{ccc}
\hline $\begin{array}{c}\text { Mushroom } \\
\text { Genus Species (Common Name) Part of the Fruiting Body }\end{array}$ & $\begin{array}{c}\text { All Glucans } \\
\text { (g/100 g Dry Matter) }\end{array}$ & $\begin{array}{c}\beta-G l u c a n s \\
\text { (g/100 g Dry Matter) }\end{array}$ \\
\hline Agaricus bisporus (white mushroom) cap & $10.1 \pm 2.2$ & $8.6 \pm 2.4$ \\
Agaricus bisporus (white mushroom) stalk & $15.0 \pm 5.0$ & $12.3 \pm 4.1$ \\
Agaricus bisporus (brown mushroom) cap & $12.3 \pm 4.5$ & $8.8 \pm 3.0$ \\
Agaricus bisporus (brown mushroom) stalk & $14.6 \pm 4.9$ & $10.1 \pm 2.2$ \\
Lentinula edodes (shiitake) cap & $20.5 \pm 6.0$ & $20.0 \pm 6.2$ \\
Lentinula edodes (shiitake) stalk & $26.7 \pm 4.0$ & $25.3 \pm 4.4$ \\
Cantharella cibarius cap & $25.3 \pm 1.7$ & $24.0 \pm 1.7$ \\
Cantharella cibarius stalk & $28.5 \pm 2.3$ & $27.0 \pm 2.5$ \\
Pleurotus ostreatus (oyster mushroom) & $25.6 \pm 1.6$ & $24.2 \pm 1.6$ \\
Pleurotus eryngii (king oyster mushroom) & $19.2 \pm 1.6$ & $15.3 \pm 1.7$ \\
Pleurotus pulmonarius (lung oyster mushroom) & $18.3 \pm 1.5$ & $15.5 \pm 1.4$ \\
Pleurotus djamor (pink oyster mushroom) & $19.4 \pm 0.6$ & $17.5 \pm 0.6$ \\
\hline
\end{tabular}

Data are reported as means and SD; all glucans are the sum of $\alpha$ - and $\beta$-glucans. Data from [64].

\section{Mushrooms beyond $\beta$-Glucans}

Considering mushrooms as a food, few epidemiological data are available.

Human studies on the association between edible mushroom consumption and cardiovascular risk were recently collected in a systematic review [66], which included analyses 
from seven observational and prospective cohort studies and randomized clinical trials, heterogeneous for interventions, outcomes, and timing. The results demonstrated no significantly different risk of total cardiovascular disease (defined as fatal cardiovascular disease and non-fatal myocardial infarction) in individuals consuming more than five servings of mushrooms per week compared to those who consumed less than one portion per month, with a follow-up greater than 2 million person-years, a finding resulting from a single large prospective study [67]; in type 2 diabetes, a small reduction of glycated hemoglobin was reported, but only based on observational studies and not confirmed by intervention trials; blood pressure reduction and favorable changes of lipid profiles were also suggested by weak evidence [66].

A randomized parallel controlled trial on hyperlipidemic subjects compared the effect of two different Japanese diets recommended for six months through periodic faceto-face nutrition education and counselling: the diet which recommended to consume more healthy foods, including mushrooms, resulted in a greater decrease of serum LDLcholesterol, triglyceride, and insulin in respect to the partial Japanese diet [68].

A large cross-sectional study on 24,236 Chinese adults, significantly associated a higher mushroom intake with lower prevalence of non-alcoholic fatty liver disorder (NAFLD), an original observation on a condition of high cardiovascular risk, which however needs to be prospectively confirmed [69].

The dietary intake of mushrooms and selenium, mainly contained in mushrooms, were studied in subjects without a history of diabetes or cardiovascular disease from the large Italian Moli-sani cohort in relation to blood glucose levels: both mushrooms and selenium resulted to be independently associated with glucose levels and high intake with higher prevalence of diabetes [70]; the authors suggested that mushrooms may contain other elements, besides selenium, responsible for the negative effect on glycemia.

On the other hand, the National Health and Nutrition Examination Survey (NHANES) 2011-2016 reported that addition of a serving of mushrooms to the diet would increase several micronutrients (dietary fibers, copper, phosphorus, potassium, selenium, zinc, riboflavin, niacin, choline, iron, thiamine, folate, and vitamin B6) in both adolescents and adults, but had no impact on energy, carbohydrate, fat, or sodium; as a consequence, the intake of a serving ( $84 \mathrm{~g}$ ) of commonly consumed mushrooms could partially correct an inadequate intake of the reported micronutrients, which is associated with adverse health effects. In the same survey, the addition of UV light-exposed mushrooms decreased the population inadequacy for vitamin D [71]. It is worth recalling that mushrooms are also a rich source of ergosterol, a precursor of vitamin D, and an important source of vitamin D itself, when mushrooms have been exposed to UV light [72]. In a previous analysis of NHANES 2001-2010, it was reported that mushrooms are rich sources of several micronutrients and that adults consuming mushrooms had higher diet quality than those who did not [73].

\section{Conclusions}

The polysaccharides $\beta$-glucans are important constituents of fungi cell walls; in the last years, their health-related effects have been studied in cellular and experimental models, to add scientifically-based knowledge to the long lasting anecdotal beneficial effects and to clarify their mechanisms.

The immunomodulatory and anti-inflammatory effects of $\beta$-glucans from different mushrooms' species have been reported and the molecular mechanisms of immune recognition by different white blood cells, have been described as mediated by specific receptors and cell signaling pathways, resulting in inflammatory immune gene expression and production of inflammatory mediators. On the other hand, in particular conditions, $\beta$-glucan extracts have been shown to modulate or reduce an ongoing inflammatory response stimulated by inflammatory stimuli, such as bacterial LPS.

These recognized activities of $\beta$-glucans from mushrooms, but also from other sources, have been considered for potential clinical use in different pathological conditions, such as 
infections of respiratory tract recurrent in children, or complications of major abdominal or thoracic surgery. Another promising application of $\beta$-glucan extracts is cancer treatment, as adjuvant of conventional therapies.

Mushrooms may affect the cardiovascular system, through their $\beta$-glucan content, but also via a number of components, such as bioactive phenolic compounds, vitamins, and mineral elements, of which mushrooms are also rich.

Although the mechanisms and heterogenous effects of the different extracted materials are not completely understood, the immunomodulatory and anti-inflammatory activities, as well as the cardiovascular protective effects are being tested in clinical studies, mainly using $\beta$-glucans from mushrooms, or concentrated extracts as nutraceuticals or in view of potential drug discovery.

These scientific and mechanistic findings more consistently support the beneficial activities of mushrooms and indications about the fungi species or molecular structures most active on the different health aspects.

The future development of mushroom knowledge would hopefully substantiate the role of this food ingredient in the context of a healthy diet, in view of preserving human health and preventing disease through a correct lifestyle.

Author Contributions: Conceptualization, writing-review and editing, C.C.; literature retrieving, S.E.; supervision, L.I. All authors have read and agreed to the published version of the manuscript.

Funding: The Article Processing Charge was funded by IoBoscoVivo Srl (www.ioboscovivo.com). No other external funding.

Data Availability Statement: Not applicable.

Acknowledgments: The authors thank Nicola Semeraro, Bari University, for his precious advice and fruitful discussion, IoBoscoVivo Srl for their interest in the topic of this review, and Antonio Iannarelli for graphical support.

Conflicts of Interest: The authors declare no conflict of interest.

\section{References}

1. Capasso, L. 5300 years ago, the Ice Man used natural laxatives and antibiotics. Lancet 1998, 352, 1864. [CrossRef]

2. Motta, F.; Gershwin, M.E.; Selmi, C. Mushrooms and immunity. J. Autoimmun. 2021, 117, 102576. [CrossRef]

3. Zheng, Z.; Zhang, Y.; Liu, Y.; Wang, J.; Cui, Z.; Pan, X.; Liu, Y.; Tang, W.; Wang, K. Metabolic degradation of lentinan in liver mediated by CYP450 enzymes and epoxide hydrolase. Carbohydr. Polym. 2021, 253, 117255. [CrossRef]

4. Zhang, Y.; Zheng, Z.; Yang, X.; Pan, X.; Yin, L.; Huang, X.; Li, Q.; Shu, Y.; Zhang, Q.; Wang, K. A sensitive and rapid radiolabelling method for the in vivo pharmacokinetic study of lentinan. Food Funct. 2018, 9, 3114-3125. [CrossRef]

5. Brandenburg, K.; Howe, J.; Gutsman, T.; Garidel, P. The expression of endotoxic activity in the Limulus test as compared to cytokine production in immune cells. Curr. Med. Chem. 2009, 16, 2653-2660. [CrossRef] [PubMed]

6. Rice, P.J.; Lockhart, B.E.; Barker, L.A.; Adams, E.L.; Ensley, H.E.; Williams, D.L. Pharmacokinetics of fungal (1-3)-beta-D-glucans following intravenous administration in rats. Int. Immunopharmacol. 2004, 4, 1209-1215. [CrossRef]

7. Odabasi, Z.; Mattiuzzi, G.; Estey, E.; Kantarjian, H.; Saeki, F.; Ridge, R.J.; Ketchum, P.A.; Finkelman, M.A.; Rex, J.H.; Ostrosky-Zeichner, L. Beta-D-glucan as a diagnostic adjunct for invasive fungal infections: Validation, cutoff development, and performance in patients with acute myelogenous leukemia and myelodysplastic syndrome. Clin. Infect. Dis. 2004, 39, 199-205. [CrossRef]

8. Yajima, Y.; Satoh, J.; Fukuda, I.; Kikuchi, T.; Toyota, T. Quantitative assay of lentinan in human blood with the limulus colorimetric test. Tohoku J. Exp. Med. 1989, 157, 145-151. [CrossRef]

9. Rahar, S.; Swami, G.; Nagpal, N.; Nagpal, M.A.; Singh, G.S. Preparation, characterization, and biological properties of $\beta$-glucans. J. Adv. Pharm. Technol. Res. 2011, 2, 94-103. [CrossRef]

10. Han, B.; Baruah, K.; Cox, E.; Vanrompay, D.; Bossier, P. Structure-Functional Activity Relationship of $\beta$-Glucans from the Perspective of Immunomodulation: A Mini-Review. Front. Immunol. 2020, 11, 658. [CrossRef]

11. Brown, G.D.; Gordon, S. Immune recognition. A new receptor for beta-glucans. Nature 2001, 413, 36-37. [CrossRef] [PubMed]

12. Gantner, B.N.; Simmons, R.M.; Canavera, S.J.; Akira, S.; Underhill, D.M. Collaborative induction of inflammatory responses by dectin-1 and Toll-like receptor 2. J. Exp. Med. 2003, 197, 1107-1117. [CrossRef] [PubMed]

13. Murphy, E.J.; Rezoagli, E.; Major, I.; Rowan, N.J.; Laffey, J.G. $\beta$-Glucan Metabolic and Immunomodulatory Properties and Potential for Clinical Application. J. Fungi 2020, 6, 356. [CrossRef] [PubMed] 
14. De Marco Castro, E.; Calder, P.C.; Roche, H.M. $\beta-1,3 / 1,6-$ Glucans and Immunity: State of the Art and Future Directions. Mol. Nutr. Food Res. 2021, 65, e1901071. [CrossRef]

15. Yadav, M.; Schorey, J.S. The beta-glucan receptor dectin-1 functions together with TLR2 to mediate macrophage activation by mycobacteria. Blood 2006, 108, 3168-3175. [CrossRef]

16. Smeekens, S.P.; Gresnigt, M.S.; Becker, K.L.; Cheng, S.C.; Netea, S.A.; Jacobs, L.; Jansen, T.; van de Veerdonk, F.L.; Williams, D.L.; Joosten, L.A.; et al. An anti-inflammatory property of Candida albicans $\beta$-glucan: Induction of high levels of interleukin-1 receptor antagonist via a Dectin-1/CR3 independent mechanism. Cytokine 2015, 71, 215-222. [CrossRef] [PubMed]

17. Ahn, H.; Jeon, E.; Kim, J.C.; Kang, S.G.; Yoon, S.I.; Ko, H.J.; Kim, P.H.; Lee, G.S. Lentinan from shiitake selectively attenuates AIM2 and non-canonical inflammasome activation while inducing pro-inflammatory cytokine production. Sci. Rep. 2017, 7, 1314. [CrossRef]

18. Sandvik, A.; Wang, Y.Y.; Morton, H.C.; Aasen, A.O.; Wang, J.E.; Johansen, F.E. Oral and systemic administration of beta-glucan protects against lipopolysaccharide-induced shock and organ injury in rats. Clin. Exp. Immunol 2007, 148, 168-177. [CrossRef]

19. Saito, M.; Nameda, S.; Miura, N.N.; Adachi, Y.; Ohno, N. Effect of SPG/indomethacin treatment on sepsis, interleukin-6 production, and expression of hepatic cytochrome P450 isoforms in differing strains of mice. J. Immunotoxicol. 2009, 6, 42-48. [CrossRef]

20. Vetvicka, V.; Vetvickova, J. Beta-glucan-indomethacin combination produces no lethal effects. Biomed. Pap. Med Fac. Univ. Palacky Olomouc Czech Repub. 2009, 153, 111-116. [CrossRef]

21. Xu, X.; Yasuda, M.; Nakamura-Tsuruta, S.; Mizuno, M.; Ashida, H. $\beta$-Glucan from Lentinus edodes inhibits nitric oxide and tumor necrosis factor- $\alpha$ production and phosphorylation of mitogen-activated protein kinases in lipopolysaccharide-stimulated murine RAW 264.7 macrophages. J. Biol. Chem. 2012, 287, 871-878. [CrossRef]

22. Jedinak, A.; Dudhgaonkar, S.; Wu, Q.L.; Simon, J.; Sliva, D. Anti-inflammatory activity of edible oyster mushroom is mediated through the inhibition of NF-KB and AP-1 signaling. Nutr. J. 2011, 10, 52. [CrossRef] [PubMed]

23. Murphy, E.J.; Masterson, C.; Rezoagli, E.; O’Toole, D.; Major, I.; Stack, G.D.; Lynch, M.; Laffey, J.G.; Rowan, N.J. $\beta$-Glucan extracts from the same edible shiitake mushroom Lentinus edodes produce differential in-vitro immunomodulatory and pulmonary cytoprotective effects-Implications for coronavirus disease (COVID-19) immunotherapies. Sci. Total Environ. 2020, 732, 139330. [CrossRef] [PubMed]

24. Johnson, E.; Førland, D.T.; Saetre, L.; Bernardshaw, S.V.; Lyberg, T.; Hetland, G. Effect of an extract based on the medicinal mushroom Agaricus blazei murill on release of cytokines, chemokines and leukocyte growth factors in human blood ex vivo and in vivo. Scand. J. Immunol. 2009, 69, 242-250. [CrossRef]

25. Ren, G.; Xu, L.; Lu, T.; Yin, J. Structural characterization and antiviral activity of lentinan from Lentinus edodes mycelia against infectious hematopoietic necrosis virus. Int. J. Biol. Macromol. 2018, 115, 1202-1210. [CrossRef] [PubMed]

26. Shahzad, F.; Anderson, D.; Najafzadeh, M. The Antiviral, Anti-Inflammatory Effects of Natural Medicinal Herbs and Mushrooms and SARS-CoV-2 Infection. Nutrients 2020, 12, 2573. [CrossRef]

27. Masterson, C.H.; Murphy, E.J.; Gonzalez, H.; Major, I.; McCarthy, S.D.; O’Toole, D.; Laffey, J.G.; Rowan, N.J. Purified $\beta$-glucans from the Shiitake mushroom ameliorates antibiotic-resistant Klebsiella pneumoniae-induced pulmonary sepsis. Lett. Appl. Microbiol. 2020, 71, 405-412. [CrossRef]

28. Basso, A.M.M.; De Castro, R.J.A.; de Castro, T.B.; Guimarães, H.I.; Polez, V.L.P.; Carbonero, E.R.; Pomin, V.H.; Hoffmann, C.; Grossi-de-Sa, M.F.; Tavares, A.H.; et al. Immunomodulatory activity of $\beta$-glucan-containing exopolysaccharides from Auricularia auricular in phagocytes and mice infected with Cryptococcus neoformans. Med. Mycol. 2020, 58, 227-239. [CrossRef]

29. Nishitani, Y.; Zhang, L.; Yoshida, M.; Azuma, T.; Kanazawa, K.; Hashimoto, T.; Mizuno, M. Intestinal Anti-Inflammatory Activity of Lentinan: Influence on IL-8 and TNFR1 Expression in Intestinal Epithelial Cells. PLoS ONE 2013, 8, e62441. [CrossRef]

30. Mao, X.; Hu, H.; Xiao, X.; Chen, D.; Yu, B.; He, J.; Yu, J.; Zheng, P.; Luo, J.; Luo, Y.; et al. Lentinan administration relieves gut barrier dysfunction induced by rotavirus in a weaned piglet model. Food Funct. 2019, 10, 2094-2101. [CrossRef]

31. Jesenak, M.; Majtan, J.; Rennerova, Z.; Kyselovic, J.; Banovcin, P.; Hrubisko, M. Immunomodulatory effect of pleuran ( $\beta$-glucan from Pleurotus ostreatus) in children with recurrent respiratory tract infections. Int. Immunopharmacol. 2013, 15, 395-399. [CrossRef] [PubMed]

32. Gaullier, J.M.; Sleboda, J.; Øfjord, E.S.; Ulvestad, E.; Nurminiemi, M.; Moe, C.; Tor, A.; Gudmundsen, O. Supplementation with a soluble $\beta$-glucan exported from Shiitake medicinal mushroom, Lentinus edodes (Berk.) singer mycelium: A crossover, placebo-controlled study in healthy elderly. Int. J. Med. Mushrooms 2011, 13, 319-326. [CrossRef] [PubMed]

33. Jesenak, M.; Hrubisko, M.; Majtan, J.; Rennerova, Z.; Banovcin, P. Anti-allergic effect of Pleuran ( $\beta$-glucan from Pleurotus ostreatus) in children with recurrent respiratory tract infections. Phytother. Res. 2014, 28, 471-474. [CrossRef] [PubMed]

34. Therkelsen, S.P.; Hetland, G.; Lyberg, T.; Lygren, I.; Johnson, E. Cytokine Levels After Consumption of a Medicinal Agaricus blazei Murill-Based Mushroom Extract, AndoSan ${ }^{\mathrm{TM}}$, in Patients with Crohn's Disease and Ulcerative Colitis in a Randomized Single-Blinded Placebo-Controlled Study. Scand. J. Immunol. 2016, 84, 323-331. [CrossRef]

35. Therkelsen, S.P.; Hetland, G.; Lyberg, T.; Lygren, I.; Johnson, E. Effect of a Medicinal Agaricus blazei Murill-Based Mushroom Extract, AndoSan ${ }^{\mathrm{TM}}$, on Symptoms, Fatigue and Quality of Life in Patients with Ulcerative Colitis in a Randomized Single-Blinded Placebo Controlled Study. PLoS ONE 2016, 11, e0150191. [CrossRef]

36. Hong, F.; Hansen, R.D.; Yan, J.; Allendorf, D.J.; Baran, J.T.; Ostroff, G.R.; Ross, G.D. Beta-glucan functions as an adjuvant for monoclonal antibody immunotherapy by recruiting tumoricidal granulocytes as killer cells. Cancer Res. 2003, 63, 9023-9031. 
37. Chan, G.C.; Chan, W.K.; Sze, D.M. The effects of beta-glucan on human immune and cancer cells. J. Hematol. Oncol. 2009 , 2, 25. [CrossRef]

38. Vetvicka, V.; Teplyakova, T.V.; Shintyapina, A.B.; Korolenko, T.A. Effects of Medicinal Fungi-Derived $\beta$-Glucan on Tumor Progression. J. Fungi 2021, 7, 250. [CrossRef]

39. Del Cornò, M.; Gessani, S.; Conti, L. Shaping the Innate Immune Response by Dietary Glucans: Any Role in the Control of Cancer? Cancers 2020, 12, 155. [CrossRef]

40. Wu, L.; Zhao, J.; Zhang, X.; Liu, S.; Zhao, C. Antitumor effect of soluble $\beta$-glucan as an immune stimulant. Int. J. Biol. Macromol. 2021, 179, 116-124. [CrossRef]

41. Thomas, M.; Sadjadian, P.; Kollmeier, J.; Lowe, J.; Mattson, P.; Trout, J.R.; Gargano, M.; Patchen, M.L.; Walsh, R.; Beliveau, M.; et al. A randomized, open-label, multicenter, phase II study evaluating the efficacy and safety of BTH1677 (1,3-1,6 beta glucan; Imprime PGG) in combination with cetuximab and chemotherapy in patients with advanced non-small cell lung cancer. Invest. New Drugs 2017, 35, 345-358. [CrossRef] [PubMed]

42. Engel-Riedel, W.; Lowe, J.; Mattson, P.; Richard Trout, J.; Huhn, R.D.; Gargano, M.; Patchen, M.L.; Walsh, R.; Trinh, M.M.; Dupuis, M.; et al. A randomized, controlled trial evaluating the efficacy and safety of BTH1677 in combination with bevacizumab, carboplatin, and paclitaxel in first-line treatment of advanced non-small cell lung cancer. J. Immunother. Cancer 2018, 6, 16. [CrossRef]

43. Segal, N.H.; Gada, P.; Senzer, N.; Gargano, M.A.; Patchen, M.L.; Saltz, L.B. A Phase II Efficacy and Safety, Open-Label, Multicenter Study of Imprime PGG Injection in Combination with Cetuximab in Patients with Stage IV KRAS-Mutant Colorectal Cancer. Clin. Colorectal Cancer 2016, 15, 222-227. [CrossRef]

44. Oba, K.; Kobayashi, M.; Matsui, T.; Kodera, Y.; Sakamoto, J. Individual patient based meta-analysis of lentinan for unresectable/recurrent gastric cancer. Anticancer. Res. 2009, 29, 2739-2745. [PubMed]

45. Ina, K.; Furuta, R.; Kataoka, T.; Kayukawa, S.; Yoshida, T.; Miwa, T.; Yamamura, Y.; Takeuchi, Y. Lentinan prolonged survival in patients with gastric cancer receiving S-1-based chemotherapy. World J. Clin. Oncol. 2011, 2, 339-343. [CrossRef] [PubMed]

46. Zhang, Y.; Zhang, M.; Jiang, Y.; Li, X.; He, Y.; Zeng, P.; Guo, Z.; Chang, Y.; Luo, H.; Liu, Y.; et al. Lentinan as an immunotherapeutic for treating lung cancer: A review of 12 years clinical studies in China. J. Cancer Res. Clin. Oncol. 2018, 144, 2177-2186. [CrossRef]

47. Steimbach, L.; Borgmann, A.V.; Gomar, G.G.; Hoffmann, L.V.; Rutckeviski, R.; de Andrade, D.P.; Smiderle, F.R. Fungal beta-glucans as adjuvants for treating cancer patients-A systematic review of clinical trials. Clin. Nutr. 2021, 40, 3104-3113. [CrossRef]

48. Sima, P.; Vannucci, L.; Vetvicka, V. $\beta$-glucans and cholesterol (Review). Int. J. Mol. Med. 2018, 41, 1799-1808. [CrossRef]

49. Caz, V.; Gil-Ramírez, A.; Largo, C.; Tabernero, M.; Santamaría, M.; Martín-Hernández, R.; Marín, F.R.; Reglero, G.; Soler-Rivas, C. Modulation of Cholesterol-Related Gene Expression by Dietary Fiber Fractions from Edible Mushrooms. J. Agric. Food Chem. 2015, 63, 7371-7380. [CrossRef] [PubMed]

50. Ho, H.V.; Sievenpiper, J.L.; Zurbau, A.; Blanco Mejia, S.; Jovanovski, E.; Au-Yeung, F.; Jenkins, A.L.; Vuksan, V. The effect of oat $\beta$-glucan on LDL-cholesterol, non-HDL-cholesterol and apoB for CVD risk reduction: A systematic review and meta-analysis of randomised-controlled trials. Br. J. Nutr. 2016, 116, 1369-1382. [CrossRef]

51. Ho, H.V.; Sievenpiper, J.L.; Zurbau, A.; Blanco Mejia, S.; Jovanovski, E.; Au-Yeung, F.; Jenkins, A.L.; Vuksan, V. A systematic review and meta-analysis of randomized controlled trials of the effect of barley $\beta$-glucan on LDL-C, non-HDL-C and apoB for cardiovascular disease risk reductioni-iv. Eur. J. Clin. Nutr. 2016, 70, 1239-1245. [CrossRef]

52. Keenan, J.M.; Goulson, M.; Shamliyan, T.; Knutson, N.; Kolberg, L.; Curry, L. The effects of concentrated barley beta-glucan on blood lipids in a population of hypercholesterolaemic men and women. Br. J. Nutr. 2007, 97, 1162-1168. [CrossRef]

53. Maki, K.C.; Galant, R.; Samuel, P.; Tesser, J.; Witchger, M.S.; Ribaya-Mercado, J.D.; Blumberg, J.B.; Geohas, J. Effects of consuming foods containing oat beta-glucan on blood pressure, carbohydrate metabolism and biomarkers of oxidative stress in men and women with elevated blood pressure. Eur. J. Clin. Nutr. 2007, 61, 786-795. [CrossRef] [PubMed]

54. Wolever, T.M.S.; Tosh, S.M.; Spruill, S.E.; Jenkins, A.L.; Ezatagha, A.; Duss, R.; Johnson, J.; Chu, Y.; Steinert, R.E. Increasing oat $\beta$-glucan viscosity in a breakfast meal slows gastric emptying and reduces glycemic and insulinemic responses but has no effect on appetite, food intake, or plasma ghrelin and PYY responses in healthy humans: A randomized, placebo-controlled, crossover trial. Am. J. Clin. Nutr. 2020, 111, 319-328. [CrossRef] [PubMed]

55. Biörklund, M.; van Reesm, A.; Mensink, R.P.; Onning. G. Changes in serum lipids and postprandial glucose and insulin concentrations after consumption of beverages with beta-glucans from oats or barley: A randomised dose-controlled trial. Eur. J. Clin. Nutr. 2005, 59, 1272-1281. [CrossRef] [PubMed]

56. McRae, M.P. Dietary Fiber Intake and Type 2 Diabetes Mellitus: An Umbrella Review of Meta-analyses. J. Chiropr. Med. 2018, 17, 44-53. [CrossRef] [PubMed]

57. Jayachandran, M.; Chen, J.; Chung, S.S.M.; Xu, B. A critical review on the impacts of $\beta$-glucans on gut microbiota and human health. J. Nutr. Biochem. 2018, 61, 101-110. [CrossRef] [PubMed]

58. EFSA Panel on Dietetic Products, Nutrition and Allergies (NDA). Scientific Opinion on the substantiation of health claims related to beta-glucans from oats and barley and maintenance of normal blood LDL-cholesterol concentrations (ID 1236, 1299), increase in satiety leading to a reduction in energy intake (ID 851, 852), reduction of post-prandial glycaemic responses (ID 821, 824), and "digestive function" (ID 850) pursuant to Article 13(1) of Regulation (EC) No 1924/2006. EFSA J. 2011, 9, 2207. 
59. EFSA Panel on Dietetic Products, Nutrition and Allergies (NDA). Scientific Opinion on the substantiation of health claims related to beta-glucans and maintenance of normal blood cholesterol concentrations (ID 754, 755, 757, 801, 1465, 2934) and maintenance or achievement of a normal body weight (ID 820, 823) pursuant to Article 13(1) of Regulation (EC) No 1924/20061. EFSA J. 2009, 7,1254 .

60. Wouk, J.; Dekker, R.F.H.; Queiroz, E.A.I.F.; Barbosa-Dekker, A.M. $\beta$-Glucans as a panacea for a healthy heart? Their roles in preventing and treating cardiovascular diseases. Int. J. Biol. Macromol. 2021, 177, 176-203. [CrossRef] [PubMed]

61. Dicks, L.; Ellingerm, S. Effect of the Intake of Oyster Mushrooms (Pleurotus ostreatus) on Cardiometabolic Parameters-A Systematic Review of Clinical Trials. Nutrients 2020, 12, 1134. [CrossRef]

62. Morales, D.; Shetty, S.A.; López-Plaza, B.; Gómez-Candela, C.; Smidt, H.; Marín, F.R.; Soler-Rivas, C. Modulation of human intestinal microbiota in a clinical trial by consumption of a $\beta$-D-glucan-enriched extract obtained from Lentinula edodes. Eur. J. Nutr. 2021, 1-17. [CrossRef]

63. Bak, W.C.; Park, J.H.; Park, Y.A.; Ka, K.H. Determination of Glucan Contents in the Fruiting Bodies and Mycelia of Lentinula edodes Cultivars. Mycobiology 2014, 42, 301-304. [CrossRef] [PubMed]

64. Sari, M.; Prange, A.; Lelley, J.I.; Hambitzer, R. Screening of beta-glucan contents in commercially cultivated and wild growing mushrooms. Food Chem. 2017, 216, 45-51. [CrossRef]

65. Mirończuk-Chodakowska, I.; Witkowska, A.M. Evaluation of Polish wild Mushrooms as Beta-Glucan Sources. Int. J. Environ. Res. Public Health 2020, 17, 7299. [CrossRef]

66. Krittanawong, C.; Isath, A.; Hahn, J.; Wang, Z.; Fogg, S.E.; Bandyopadhyay, D.; Jneid, H.; Virani, S.S.; Tang, W.H.W. Mushroom Consumption and Cardiovascular Health: A Systematic Review. Am. J. Med. 2021, 134, 637-642. [CrossRef] [PubMed]

67. Lee, D.H.; Yang, M.; Giovannucci, E.L.; Sun, Q.; Chavarro, J.E. Mushroom consumption, biomarkers, and risk of cardiovascular disease and type 2 diabetes: A prospective cohort study of US women and men. Am. J. Clin. Nutr. 2019, 110, 666-674. [CrossRef]

68. Maruyama, C.; Shijo, Y.; Kameyama, N.; Umezawa, A.; Sato, A.; Nishitani, A.; Ayaori, M.; Ikewaki, K.; Waki, M.; Taramoto, T. Effects of Nutrition Education Program for the Japan Diet on Serum LDL-Cholesterol Concentration in Patients with Dyslipidemia: A Randomized Controlled Trial. J. Atheroscler. Thromb. 2021, 60376. [CrossRef]

69. Zhang, S.; Gu, Y.; Lu, M.; Fu, J.; Zhang, Q.; Liu, L.; Meng, G.; Yao, Z.; Wu, H.; Bao, X.; et al. Association between edible mushroom intake and the prevalence of newly diagnosed non-alcoholic fatty liver disease: Results from the TCLSIH Cohort Study in China. Br. J. Nutr. 2019, 123, 104-112. [CrossRef]

70. Pounis, G.; Costanzo, S.; Persichillo, M.; De Curtis, A.; Sieri, S.; Vinceti, M.; Zito, F.; Di Castelnuovo, A.F.; Donati, M.B.; de Gaetano, G.; et al. Mushroom and dietary selenium intakes in relation to fasting glucose levels in a free-living Italian adult population: The Moli-sani Project. Diabetes Metab. 2014, 40, 34-42. [CrossRef]

71. Fulgoni, V.L., 3rd; Agarwal, S. Nutritional impact of adding a serving of mushrooms on usual intakes and nutrient adequacy using National Health and Nutrition Examination Survey 2011-2016 data. Food Sci. Nutr. 2021, 9, 1504-1511. [CrossRef] [PubMed]

72. Cardwell, G.; Bornman, J.F.; James, A.P.; Black, L.J. A Review of Mushrooms as a Potential Source of Dietary Vitamin D. Nutrients 2018, 10, 1498. [CrossRef] [PubMed]

73. O'Neil, C.E.; Nicklas, T.A.; Fulgoni, V.L., 3rd. Mushroom intake is associated with better nutrient intake and diet quality: 2001-2010 National Health and Nutrition Examination Survey. J. Nutr. Food Sci. 2013, 3, 229. [CrossRef] 